\title{
Sürekli Mıknatıslı Senkron Motorun Alan Yönlendirmeli Kontrolü ve Kontrol İçin Geliştirilen Özel Amaçlı Motor Sürücüsünün Tasarımı ve Prototip Üretimi
}

\author{
Hüseyin Cemre YILMAZ1 ${ }^{1}$ Esra KANDEMIR BEŞER ${ }^{2 *}$ \\ ${ }^{1}$ Yllmaz Redüktör San. ve Tic. A.Ş., Atatürk Mh., Lozan Cd., 34522, İstanbul, Türkiye \\ ${ }^{2}$ Kocaeli Üniversitesi, Mühendislik Fakültesi, Elektrik Mühendisliği Bölümü, Kocaeli, Türkiye \\ (ORCID: 0000-0001-9578-3447) (ORCID: 0000-0002-4305-3415)
}

\begin{abstract}
$\ddot{\mathbf{O z}}$
Son dönemde elektrik makinaları alanında yapılan çalışmalar neticesinde popülerlik kazanan sürekli mıknatıslı senkron motorlar (SMSM), günümüzde endüstriyel uygulamalardan son kullanıcı ürünlerine kadar geniş bir kullanım alanına sahiptir. Sürekli mıknatıslı senkron motorların uygun kontrolü ile endüstride sıklıkla karşılaşılan birçok uygulama, robotik sistemler, talaşlı imalatın temel yapı taşı haline gelmiş metal işleme tezgâhları vb. uygulamalarda, düşük hacimde yüksek performans elde etmek mümkün hale gelmiştir. Bunun yanı sıra yine endüstride karşılaşılan yüksek dinamizm ve/veya hassas pozisyon kontrolü gerektiren uygulamalarda da sıklıkla sürekli mıknatıslı senkron motorlar tercih edilmektedir. Sürekli mıknatıslı senkron motorların yüksek performanslı kontrolünü sağlamak amacıyla geliştirilen birçok yöntem bulunmakla birlikte, bunlardan en çok öne çıkan iki tanesi Alan Yönlendirmeli Kontrol ve Doğrudan Moment Kontrolü teknikleridir. Alan yönlendirmeli kontrol tekniğinin pozisyon geri besleme elemanı ile birlikte uygulanması durumunda çoğu uygulamada ihtiyaç duyulan yüksek kalkış momenti, düşük devirlerde yüksek hız kararlılığ 1 ve farklı hız referans değerlerine karşı dinamik tepki ihtiyaçlarını karşılayabilmesi bu tekniğin birçok endüstriyel hız kontrol cihazında da tercih edilmesine sebep olmuştur. Bu çalışmada, alan kontrolü yapmak üzere geliştirilen mikro denetleyici tabanlı motor sürücüsü üzerinde alan yönlendirmeli kontrol tekniği uygulanarak, miline artımsal enkoder bağlı bir sürekli mıknatıslı senkron motorun hız kontrolü ve ayrıca dolaylı moment kontrolü sağlanmıştır. Hız kontrolü ve moment kontrolü yapılırken sistemin verilen referans değerlere karşı tepkisi ölçülmüştür. Yapılan ölçümler farklı kontrol parametreleri ile tekrarlanarak karşılaştırmalar yapılmıştır.
\end{abstract}

Anahtar kelimeler: Alan Yönlendirmeli Kontrol, Motor Sürücüsü, Hız Kontrolü, Moment Kontrolü, PI Kontrol, Sürekli Miknatıslı Senkron Motor.

\section{Field Oriented Control of Permanent Magnet Synchronous Motor and Design and Prototype Production of a Special Purpose Motor Drive}

\begin{abstract}
Permanent magnet synchronous motors (PMSMs) are getting popularity thanks to too many studies in the electric machinery field, and can be used in many applications from consumer products to industry. It is possible to get high performance in small volumes with using proper permanent magnet synchronous motor control methods, in frequently encountered industry applications like robotic systems, metal processing workbenches which has become most important part of the machining processes. And also, permanent magnet synchronous motors are mostly preferred for such applications which need high dynamism and/or high precision position control in industry. Although there are many different techniques to control permanent magnet synchronous motors with high performance, in the literature Field Oriented Control and Direct Torque Control stand out. Field oriented control with position feedback sensor is able to provide high start-up torque, higher speed control accuracy at low speeds and dynamic response against to different speed set values, which are needed for most of applications, thus it is widely preferred in industrial variable speed drives. On a newly developed microcontroller based motor drive, field oriented control technique is applied to a permanent magnet synchronous motor equipped with an incremental encoder to control motor speed and torque. The response of motor against to different set points is measured while working in speed control and torque control modes. Measurements are repeated with different control parameters and the results are compared with each other.
\end{abstract}

Keywords: Field Oriented Control, Motor Drive, Speed Control, Torque Control, PI Control, Permanent Magnet Synchronous Motors.

\footnotetext{
* Sorumlu yazar: esrakandemir@kocaeli.edu.tr

Geliş Tarihi:22.12.2020, Kabul Tarihi: 06.08.2021
} 


\section{Giriş}

Türkiye sanayisinde toplam elektrik enerjisi tüketiminin yaklaşık \%70'inin, başka bir açıdan bakılacak olursa ülke genelinde üretilen toplam elektrik enerjisinin yaklaşık \%36'sının elektrik motorları sistemlerinde kullanıldığı bilinmektedir [1]. Bunun yanında Türkiye sanayisinde kullanılan motorların büyük çoğunluğunun "IE1 Standart Verimlilik" ve altı verimlilik sınıfına sahip olduğu bilinmektedir [1]. Üç fazlı asenkron motorlar ile kıyaslandığında verimlilik ve hacim/güç oranı bakımından daha avantajlı olan sürekli mıknatıslı senkron motorlar (SMSM) gün geçtikçe daha fazla kullanım oranına sahip olmaktadır. SMSM' lerin bazı endüstriyel uygulamalarda özellikle tercih edilmelerinin bir sebebi de yüksek dinamizm gerektiren uygulamalarda aynı güçteki üç fazlı asenkron motorlara kıyasla daha az hacimde aynı momenti üretebilmesi ve boyutlarından ötürü daha düşük atalete sahip olmasıdır. Ancak SMSM'ler, üç fazlı asenkron motorlarda olduğu gibi elektrik şebekesinden doğrudan yol verme metodu ile kullanılamazlar. Bu nedenle SMSM' lerin uygun biçimde çalıştırılabilmesi için özel kontrol yöntemleri geliştirilmiştir. Endüstriyel ürünlerde kullanım oranı göz önünde bulundurulduğunda, en popüler SMSM kontrol yöntemleri arasında Alan Yönlendirmeli Kontrol (AYK) ve Doğrudan Moment Kontrolü (DMK) say1labilir [2,3].

Günümüzde alan yönlendirmeli kontrol tekniğinin endüstriyel alanda kullanılmak üzere tasarlanan yeni ürünlerde dahi tercih ediliyor olması, bu teorinin sahada uygulanabilir ve aynı zamanda geliştirmeye açık olduğunu göstermektedir. Alan yönlendirmeli kontrol konusunda literatürde pek çok çalışma bulunmaktadır [4-10]. Bu çalışmalarda genellikle DSP mikrodenetleyici tabanlı motor sürücüleri kullanılmaktadır [4, 11-14]. Son yıllarda ise alan yönlendirmeli kontrol çalışmalarında STM mikrodenetleyici tabanlı sürücülerin de ön plana çıktığı görülmektedir [15-17]. STM mikrodenetleyiciler, düşük maliyetli, düşük güç tüketimli, yüksek işlem kapasiteli olmaları ve hızlı cevap verme yetenekleri sayesinde motor sürücülerinde kullanılan pahalı işlemcilere bir alternatif teşkil etmektedir.

$\mathrm{Bu}$ çalışmada, alan yönlendirmeli kontrol yöntemi temel alınarak endüstriyel bir SMSM'nin hız/pozisyon geri beslemeli kapalı çevrim kontrolünü sağlamak hedeflenmiştir. Bu amaçla STM mikrodenetleyici tabanlı kontrol ünitesine sahip, IGBT (Insulated Gate Bipolar Transistor) teknolojisi kullanan özel amaçlı üç fazlı bir motor sürücüsü tasarlanmış ve gerçeklenmiştir. Tasarlanan sürücü STM tabanlı olduğundan literatürdeki pahalı motor sürücülerine göre düşük maliyetli fakat alan yönlendirmeli kontrol işlemini başarıyla uygulayabilen bir alternatif olarak ortaya konmuştur. SMSM ve motor sürücüsü birlikte kullanılarak deneysel çalışmalar yapılmış ve sonuçlara yer verilmiştir.

\section{Materyal ve Metot}

Alan yönlendirmeli kontrol metodunu gerçek bir SMSM üzerinde uygulamaya geçirebilmek ve makinanın kapalı çevrim kontrolünü gerçekleştirebilmek için ilk olarak SMSM'nin matematiksel modelinin anlaşılması gerekmektedir. Motorun matematiksel modeli kullanılan matematiksel dönüşümler sayesinde $\mathrm{d}$ ve q ekseni akım bileşenleri cinsinden iki fazlı rotor referans düzleminde ifade edilebilir. Alan yönlendirmeli kontrol tekniği kullanılarak çeşitli kontrolör yapıları vasıtasıyla motorun üreteceği moment veya motorun hızı kontrol edilebilmektedir. Alan yönlendirmeli kontrol tekniğinin gerçeklenmesinde tercih edilen modülasyon tekniği, uzay vektör modülasyonu tekniğidir. Bu teknik, motor sürücüsünün evirici devresi için kullanılmaktadır. Motor sürücü devresindeki donanım ve yazılım ile SMSM'nin alan yönlendirmeli kontrolü gerçekleştirilerek deneysel çalışmalar yapılmakta ve SMSM tasarlanan bir deney seti üzerinde test edilebilmektedir.

Bu kısımda ilk olarak SMSM'ler ile ilgili genel bilgiler verilerek makinanın matematiksel modeli oluşturulmuştur. Alan yönlendirmeli kontrol metodu anlatılarak, tasarlanan sürücü detaylı olarak ele alınmıştır. Deneysel çalışmalarda kullanılan SMSM, motor sürücüsü prototipi ve deney seti hakkında bilgiler verilmiştir.

\subsection{Sürekli Mıknatıslı Senkron Motorlar}

Geçmişten günümüze elektrik makinaları alanında yapılan çalışmalar sonucunda endüstrinin kullanımına sunulmuş birçok elektrik makinası türü mevcuttur. Mıknatıs teknolojisinde yaşanan gelişmeler ile rotorunda mıknatıs malzemenin bulunduğu SMSM'ler yüksek performans gerektiren 
birçok uygulama için tercih edilmektedir. Bu makinaların yapılarında firça ve kollektör yapısının bulunmaması, hacim başına üretilen momentin fazla olması, asenkron motorlara göre verimlerinin yüksek olması gibi birçok avantajı bulunmaktadır. SMSM'ler alternatif akım motorlarından, senkron motorlar ailesi içerisinde yer almaktadır.

\subsubsection{Sürekli Mıknatıslı Senkron Motorların Matematiksel Modeli}

Sürekli mıknatıslı senkron motorların yüksek performanslı sayısal kontrolünü ve benzetim çalışmalarını gerçekleştirebilmek için motor matematiksel modelinin anlaşılmasına ihtiyaç duyulmaktadır. Alan yönlendirmeli kontrol tekniğinin gerçekleştirilebilmesi için, bu çalışmada üç fazlı sürekli mıknatıslı senkron motorun modeli rotor referans düzlemi temel alınarak oluşturulmuştur.

İki fazlı rotor referans düzleminde motorun matematiksel modelinin oluşturulabilmesi için bir takım matematiksel dönüşümlere ihtiyaç duyulmaktadır. Bu dönüşümler Park dönüşümü, ters Park dönüşümü, Clarke dönüşümü ve ters Clarke dönüşümü olarak isimlendirilmektedirler.

\subsubsection{Clarke Dönüşümü}

Clarke dönüşümü, Şekil 1'de görüldüğü gibi üç fazlı bir sistemin, iki fazlı ortogonal düzlemde (stator referans düzleminde) ifade edilebilmesi için geliştirilen matematiksel bir dönüşümdür. Clarke dönüşümü, ayrıca $\alpha \beta 0$ (Alpha-Beta-Zero) dönüşümü olarak da bilinmektedir [18].

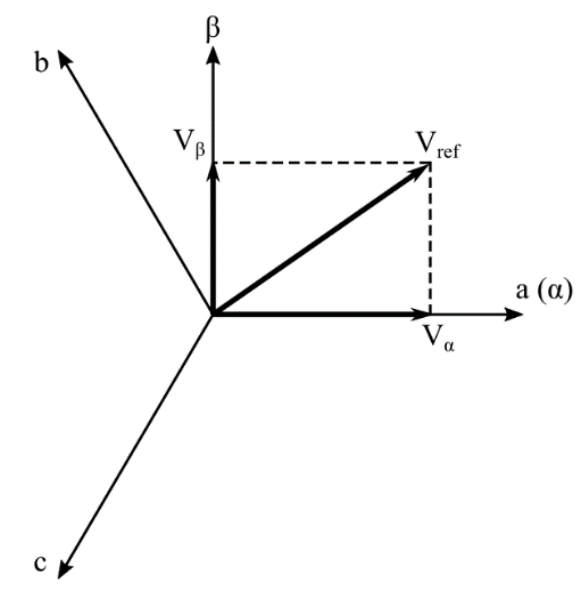

Şekil 1. Üç fazlı bir sistemin bileşke vektörünün $\alpha \beta 0$ düzleminde gösterimi [18].

Clarke dönüşümünün genelleştirilmiş matematiksel ifadesi Denklem (1)'de gösterilmektedir

$$
\mathrm{v}_{\alpha \beta 0}(\mathrm{t})=\frac{2}{3}\left[\begin{array}{ccc}
1 & -\frac{1}{2} & -\frac{1}{2} \\
0 & \frac{\sqrt{3}}{2} & -\frac{\sqrt{3}}{2} \\
\frac{1}{2} & \frac{1}{2} & \frac{1}{2}
\end{array}\right]\left[\begin{array}{l}
\mathrm{v}_{\mathrm{a}}(\mathrm{t}) \\
\mathrm{v}_{\mathrm{b}}(\mathrm{t}) \\
\mathrm{v}_{\mathrm{c}}(\mathrm{t})
\end{array}\right]
$$

\subsubsection{Ters Clarke Dönüşümü}

Ters Clarke dönüşümü, iki fazlı ortogonal düzlemde (stator referans düzleminde) ifade edilen bir uzay vektörünün üç fazlı bir sistemde ifade edilebilmesi için geliştirilen matematiksel bir dönüşümdür. Ters Clarke dönüşümünün genelleştirilmiş matematiksel ifadesi Denklem (2)'de gösterilmektedir [18]. 


$$
\mathrm{v}_{\mathrm{abc}}(\mathrm{t})=\left[\begin{array}{ccc}
1 & 0 & 1 \\
-\frac{1}{2} & \frac{\sqrt{3}}{2} & 1 \\
-\frac{1}{2} & -\frac{\sqrt{3}}{2} & 1
\end{array}\right]\left[\begin{array}{l}
\mathrm{v}_{\alpha}(\mathrm{t}) \\
\mathrm{v}_{\beta}(\mathrm{t}) \\
\mathrm{v}_{0}(\mathrm{t})
\end{array}\right]
$$

\subsubsection{Park Dönüşümü}

Park dönüşümü, iki fazlı ortogonal düzlemde ifade edilen bir vektörün, sabit düzlemde (rotor referans düzleminde) ifade edilebilmesi için geliştirilen matematiksel bir dönüşümdür. Park dönüşümünün genelleştirilmiş matematiksel ifadesi Denklem (3)'te gösterilmektedir [18].

$$
v_{d q 0}(t)=\left[\begin{array}{ccc}
\cos (\theta) & \sin (\theta) & 0 \\
-\sin (\theta) & \cos (\theta) & 0 \\
0 & 0 & 1
\end{array}\right]\left[\begin{array}{c}
v_{\alpha}(t) \\
v_{\beta}(t) \\
v_{0}(t)
\end{array}\right]
$$

\subsubsection{Ters Park Dönüșümü}

Ters Park dönüşümü, sabit düzlemde (rotor referans düzleminde) ifade edilen bir vektörün, iki fazlı ortogonal düzlemde (stator referans düzleminde) ifade edilebilmesi için geliştirilen matematiksel bir dönüşümdür. Ters Park dönüşümünün genelleştirilmiş matematiksel ifadesi Denklem (4)’te gösterilmektedir [18].

$$
\mathrm{v}_{\alpha \beta 0}(\mathrm{t})=\left[\begin{array}{ccc}
\cos (\theta) & -\sin (\theta) & 0 \\
\sin (\theta) & \cos (\theta) & 0 \\
0 & 0 & 1
\end{array}\right]\left[\begin{array}{c}
\mathrm{v}_{\mathrm{d}}(\mathrm{t}) \\
\mathrm{v}_{\mathrm{q}}(\mathrm{t}) \\
\mathrm{v}_{0}(\mathrm{t})
\end{array}\right]
$$

\subsubsection{Motor Matematiksel Modeli}

Sabit düzlemde (rotor referans düzleminde) motor matematiksel modelinin elde edilebilmesi için, motorun sabit düzlem d (direct) ve q (quadrature) eksenlerinde tanımlanan eşdeğer devre modellerinden yararlanılabilmektedir. Sabit düzlem d ve q eşdeğer devreleri sırasıyla Şekil 2'de gösterilmektedir [19].

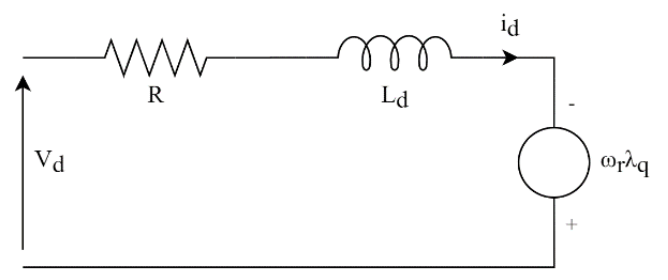

(a)

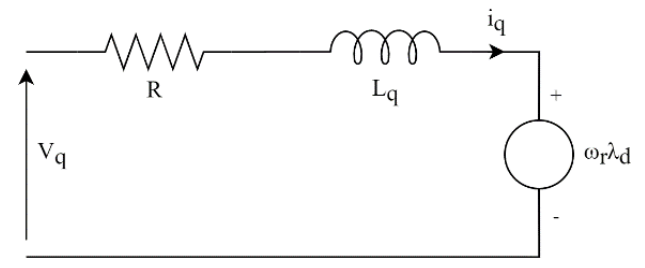

(b)

Şekil 2. SMSM (a) d ekseni eşdeğer devresi (b) q ekseni eşdeğer devresi

Şekil 2'de verilen d ve q ekseni eşdeğer devreleri temel alınarak ilgili çevre gerilim eşitlikleri Denklem (5) ve Denklem (6)'daki gibi bulunabilmektedir [19].

$$
v_{d}(t)=R \cdot i_{d}(t)+L_{d} \cdot \frac{d i_{d}}{d t}-\omega_{r} \cdot \lambda_{q}
$$




$$
\mathrm{v}_{\mathrm{q}}(\mathrm{t})=\mathrm{R} \cdot \mathrm{i}_{\mathrm{q}}(\mathrm{t})+\mathrm{L}_{\mathrm{q}} \cdot \frac{\mathrm{di}_{\mathrm{q}}}{\mathrm{dt}}+\omega_{\mathrm{r}} \cdot \lambda_{\mathrm{d}}
$$

Gerilim denklemlerinde $V_{d}$ ve $V_{q}$, $d$ ve $q$ ekseni stator gerilimleri, $i_{d}$ ve $i_{q}$, $d$ ve $q$ ekseni stator akımları, $\mathrm{L}_{\mathrm{d}}, \mathrm{L}_{\mathrm{q}}$ ve $\lambda_{\mathrm{d}}, \lambda_{\mathrm{q}}$ ise sirasıyla $\mathrm{d}$ ve ekseni stator endüktansları ve akılarıdır. R stator direncini, $\omega_{\mathrm{r}}$ ise rotor elektriksel hızını belirtir. Ayrıca d ve q ekseni akıları Denklem (7) ve Denklem (8)'deki gibi tanımlanabilmektedir [19].

$$
\begin{aligned}
& \lambda_{d}=L_{d} \cdot i_{d}+\lambda_{m} \\
& \lambda_{q}=L_{q} \cdot i_{q}
\end{aligned}
$$

d ekseni akı denklemindeki $\lambda_{\mathrm{m}}$ makinadaki mıknatıs akısıdır. Bunun yanında üretilen elektromanyetik momentin ifadesi $\left(\mathrm{T}_{\mathrm{e}}\right)$ ise Denklem (9)'daki gibi tanımlanabilmektedir [3].

$$
\mathrm{T}_{\mathrm{e}}=\frac{3}{2} \cdot \mathrm{p} \cdot\left[\left(\lambda_{\mathrm{m}} \cdot \mathrm{i}_{\mathrm{q}}\right)+\left(\mathrm{L}_{\mathrm{d}}-\mathrm{L}_{\mathrm{q}}\right) \cdot\left(\mathrm{i}_{\mathrm{d}} \cdot \mathrm{i}_{\mathrm{q}}\right)\right]
$$

Elektromanyetik moment denklemindeki p çift kutup sayısıdır. Ayrıca sabit akılı çalışma durumunda, $i_{d}$ akımının sıfır olduğu durumda üretilen elektromanyetik momentin ifadesi Denklem (10)'daki gibi olacaktır [3]. Buna ek olarak, yüzey montaj sürekli mıknatıslı senkron motorlarda d ve q ekseni endüktanslarının birbirine eşit olması nedeniyle rotor üzerinde relüktans momenti de oluşmamaktadır.

$$
\mathrm{T}_{\mathrm{e}}=\frac{3}{2} \cdot \mathrm{p} \cdot\left(\lambda_{\mathrm{m}} \cdot \mathrm{i}_{\mathrm{q}}\right)
$$

Makina matematiksel modeli a,b,c faz sisteminden gerekli matematiksel dönüşümler kullanılarak d,q sistemine dönüştürüldüğ̈̈ için model oldukça basitleşmekte ve serbest uyarmalı doğru akım motor modeline benzemektedir. Denklem (10)'dan da görüldüğü gibi motorda üretilen elektromanyetik moment $i_{q}$ akımına bağlıdır.

Motorun mekanik denklemi ise Denklem (11)'deki gibi tanımlanabilmektedir [19].

$$
\mathrm{T}_{\mathrm{e}}=\mathrm{T}_{\mathrm{L}}+\mathrm{B} \cdot \omega_{\mathrm{m}}+\mathrm{J} \cdot \frac{\mathrm{d} \omega_{\mathrm{m}}}{\mathrm{dt}}
$$

Mekanik denklemdeki $T_{L}$ yük momenti, B sürtünme katsayısı, $\mathrm{j}$ rotor atalet momenti, $\omega_{\mathrm{m}}=\omega_{\mathrm{r}} / \mathrm{p}$ ise rotor mekanik hızıdır.

\subsection{Alan Yönlendirmeli Kontrol Metodu}

Hareket kontrolüne ihtiyaç duyulan uygulamaların büyük çoğunluğunda elektrik motorlarından faydalanılmaktadır. Özellikle yüksek performanslı hareket kontrolü gerektiren uygulamalarda ise SMSM'ler sıklıkla tercih edilmektedir. SMSM'lerin yüksek performanslı kontrolünün sağlanabilmesi için geliştirilen kontrol tekniklerinden en popüler olanı ise alan yönlendirmeli kontroldür. Şekil 3'te alan yönlendirmeli kontrole ait prensip şeması görülmektedir [6].

Alan yönlendirmeli kontrol tekniği kullanılarak çeşitli kontrolör yapıları vasıtasıyla motorun üreteceği moment veya motorun hızı kontrol edebilir ya da sınırlandırabilir. Şekil 3 'te gösterilen prensip şeması incelendiğinde, motora uygulanan gerilimin q ve d ekseni bileşenleri PI kontrolör yapıları ile değiştirilerek, motorun q ve d ekseni akımlarının kontrol edilmesinin amaçlandığı görülebilmektedir. Alan yönlendirmeli kontrol tekniğinde q ekseni akımı motor tarafından üretilecek momenti, $\mathrm{d}$ ekseni akımı ise stator tarafından üretilecek manyetik akıyı belirlemektedir. Bu durumda q ekseni akımını kontrol eden PI kontrolör yapısının dolaylı olarak motorun üreteceği momenti kontrol ettiği anlaşılmaktadır. Alan yönlendirmeli kontrol tekniği kullanılan bir sistemde moment kontrolü yapılmak 
istendiği durumda, q ekseni akımı ayar değerinin kontrolü kullanıcıya bırakılarak, bazı özel uygulamaların gerçekleştirilebilmesi mümkün kılınmaktadır.

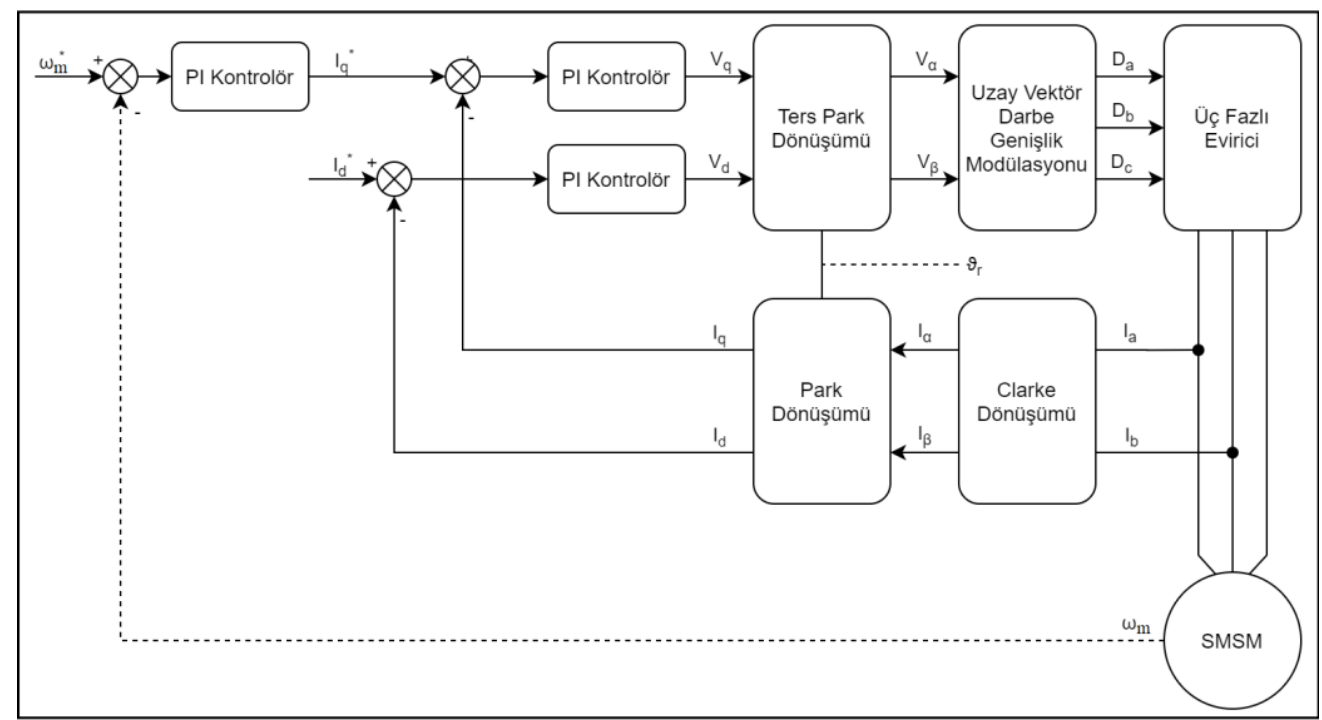

Şekil 3. Alan yönlendirmeli kontrol prensip şeması

Alan yönlendirmeli kontrolün motora uygulamak üzere ihtiyaç duyduğu değişken genlikli ve frekanslı gerilim sinyallerinin üretilebilmesi için kullanılacak olan eviricinin kontrolünde birçok farklı modülasyon tekniği kullanılabilmektedir. Alan yönlendirmeli kontrol tekniğinin gerçeklenmesinde tercih edilen modülasyon tekniği, uzay vektör modülasyonu tekniğidir.

\subsubsection{Uzay Vektör Modülasyonu}

Uzay vektör modülasyonu, Şekil 4'te verilen evirici topolojisinde görülen üç faz yarım köprü anahtarlama elemanlarının iletimde veya kesimde olması durumlarına göre üretilebilecek sekiz adet gerilim vektörünün kullanılması ile evirici çıkışında istenen gerilim vektörünün elde edilmesine dayanan bir modülasyon tekniğidir [20].

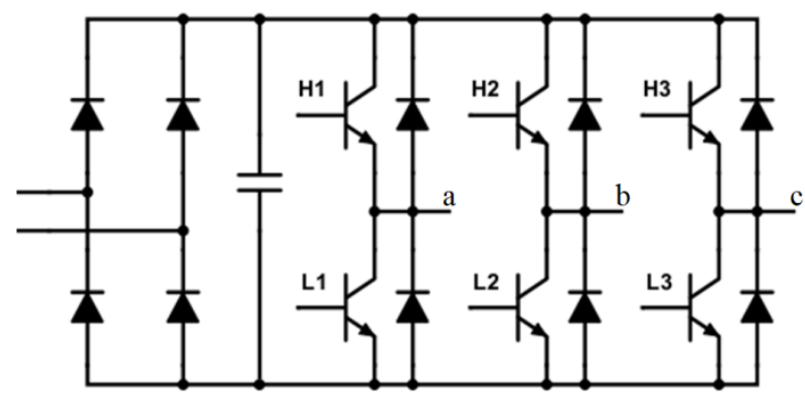

Şekil 4. 3 fazlı evirici topolojisi

\subsubsection{Uzay Vektör Darbe Genişlik Modülasyonu}

Uzay vektör darbe genişlik modülasyonu, darbe genişlik modülasyonu sinyallerinin doluluk-boşluk oranlarının belirlenmesinde uzay vektörlerinin uzunluklarının ve yönelim açlarının kullanılarak anahtarlama sinyallerinin üretilebilmesine olanak sağlamak amacıyla geliştirilmiş bir tekniktir.

UVDGM çıkışı, üç fazlı evirici üzerindeki anahtarlama elemanlarına uygulandığında sekiz temel gerilim vektörü oluşmaktadır. Bu temel gerilim vektörleri Şekil 5’te gösterilmektedir [21]. 


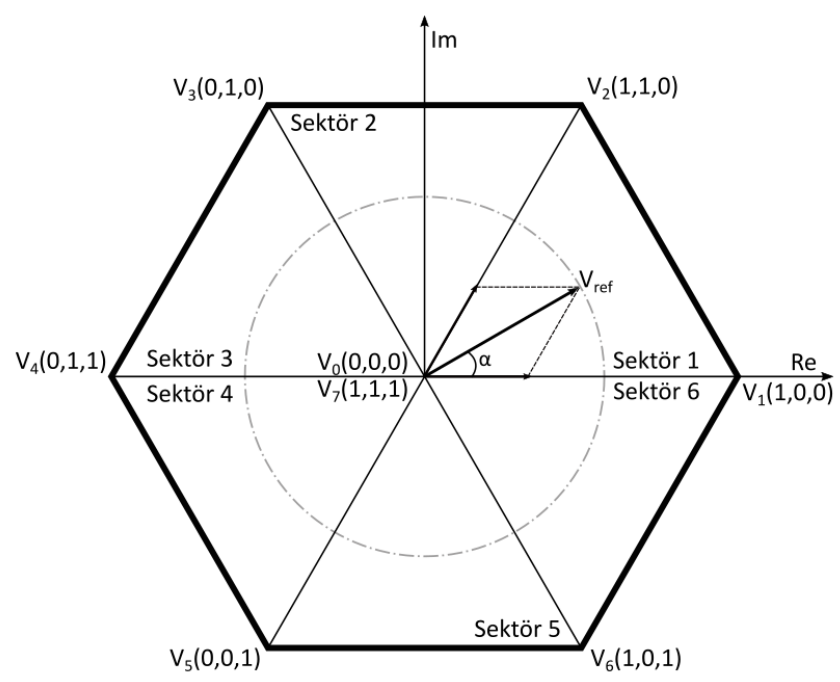

Şekil 5. Uzay vektör modülasyonu temel gerilim vektörleri

Şekilde görülen üç fazlı evirici prensip şemasında bulunan anahtarlama elemanlarının durumlarına göre, evirici çıkışında elde edilebilecek gerilim vektörlerinin ifade edilebileceği eşitlik Denklem (12)'deki gibi tanımlanabilmektedir [22].

$$
\mathrm{V}_{\text {ref }}\left(\mathrm{H}_{1}, \mathrm{H}_{2}, \mathrm{H}_{3}\right)=\mathrm{V}_{\mathrm{da}}\left(\mathrm{H}_{1} \cdot \mathrm{e}^{\mathrm{j} 0}+\mathrm{H}_{2} \cdot \mathrm{e}^{\mathrm{j} \frac{2 \pi}{3}}+\mathrm{H}_{3} \cdot \mathrm{e}^{\mathrm{j} \frac{-2 \pi}{3}}\right)
$$

\subsubsection{Anahtarlama Sürelerinin Hesaplanması}

Uzay vektör darbe genişlik modülasyonu tekniği kullanılarak ilgili referans vektörün üretilebilmesi için, referans vektörün bulunduğu sektörün belirlenmesinin ardından sektörü oluşturan temel gerilim vektörlerinin referans vektör üzerindeki ağırlıklarının hesaplanması gerekmektedir. Sektörü oluşturan iki temel gerilim vektörünün ve sıfır gerilim vektörlerinin referans vektör üzerindeki ağırlıkları hesaplanarak çıkışa ne kadar süre boyunca uygulanmaları gerektiği tespit edildikten sonra hesaplanan darbe genişlik modülasyonu doluluk oranları kullanılarak evirici çıkışında istenen referans gerilim vektörü elde edilebilecektir. Herhangi bir sektördeki referans gerilim vektörünün üretilebilmesi için gerekli anahtarlama sürelerinin hesaplanmasında kullanılacak eşitlikler Tablo 1'de, ilgili referans gerilim vektörünün üretilebilmesi için gerekli doluluk oranları eşitlikleri Tablo 2'de verilmiştir [22].

Tablo 1. Anahtarlama sürelerinin hesaplanması

\begin{tabular}{ccc}
\hline Sektör & \multicolumn{1}{c}{$\mathrm{t}_{\mathrm{a}}$} & $\frac{\mathrm{t}_{\mathrm{b}}}{\mathrm{V}_{\mathrm{da}}} \cdot \frac{2}{\sqrt{3}}$ \\
\hline 1 & $\frac{\mathrm{V}_{\alpha}}{\mathrm{V}_{\mathrm{da}}}-\frac{\mathrm{V}_{\beta}}{\mathrm{V}_{\mathrm{da}}} \cdot \frac{1}{\sqrt{3}}$ & $\frac{\mathrm{V}_{\beta}}{\mathrm{V}_{\mathrm{da}}} \cdot \frac{1}{\sqrt{3}}-\frac{\mathrm{V}_{\alpha}}{\mathrm{V}_{\mathrm{da}}}$ \\
3 & $\frac{\mathrm{V}_{\alpha}}{\mathrm{V}_{\mathrm{da}}}+\frac{\mathrm{V}_{\beta}}{\mathrm{V}_{\mathrm{da}}} \cdot \frac{1}{\sqrt{3}}$ & $-\frac{\mathrm{V}_{\alpha}}{\mathrm{V}_{\mathrm{da}}}-\frac{\mathrm{V}_{\beta}}{\mathrm{V}_{\mathrm{da}}} \cdot \frac{1}{\sqrt{3}}$ \\
4 & $\frac{\mathrm{V}_{\beta}}{\mathrm{V}_{\mathrm{da}}} \cdot \frac{2}{\sqrt{3}}$ & $-\frac{\mathrm{V}_{\beta}}{\mathrm{V}_{\mathrm{da}}} \cdot \frac{2}{\sqrt{3}}$ \\
5 & $-\frac{\mathrm{V}_{\alpha}}{\mathrm{V}_{\mathrm{da}}}+\frac{\mathrm{V}_{\beta}}{\mathrm{V}_{\mathrm{da}}} \cdot \frac{1}{\sqrt{3}}$ & $-\frac{\mathrm{V}_{\beta}}{\mathrm{V}_{\mathrm{da}}} \cdot \frac{1}{\sqrt{3}}+\frac{\mathrm{V}_{\alpha}}{\mathrm{V}_{\mathrm{da}}}$ \\
6 & $-\frac{\mathrm{V}_{\alpha}}{\mathrm{V}_{\mathrm{da}}}-\frac{\mathrm{V}_{\beta}}{\mathrm{V}_{\mathrm{da}}} \cdot \frac{1}{\sqrt{3}}$ & $\frac{\mathrm{V}_{\alpha}}{\mathrm{V}_{\mathrm{da}}}+\frac{\mathrm{V}_{\beta}}{\mathrm{V}_{\mathrm{da}}} \cdot \frac{1}{\sqrt{3}}$ \\
\hline
\end{tabular}


Tablo 2. Faz doluluk oranlarının hesaplanması

\begin{tabular}{cccc}
\hline Sektör & $\mathrm{D}_{\mathrm{a}}$ & $\mathrm{D}_{\mathrm{b}}$ & $\mathrm{D}_{\mathrm{c}}$ \\
\hline 1 & $t_{0} / 2+\mathrm{t}_{\mathrm{a}}+\mathrm{t}_{\mathrm{b}}$ & $t_{0} / 2+\mathrm{t}_{\mathrm{b}}$ & $t_{0} / 2$ \\
2 & $t_{0} / 2+\mathrm{t}_{\mathrm{a}}$ & $t_{0} / 2+\mathrm{t}_{\mathrm{a}}+\mathrm{t}_{\mathrm{b}}$ & $t_{0} / 2$ \\
3 & $t_{0} / 2$ & $t_{0} / 2+\mathrm{t}_{\mathrm{a}}+\mathrm{t}_{\mathrm{b}}$ & $t_{0} / 2+\mathrm{t}_{\mathrm{b}}$ \\
4 & $t_{0} / 2$ & $t_{0} / 2+\mathrm{t}_{\mathrm{a}}$ & $t_{0} / 2+\mathrm{t}_{\mathrm{a}}+\mathrm{t}_{\mathrm{b}}$ \\
5 & $t_{0} / 2+\mathrm{t}_{\mathrm{b}}$ & $t_{0} / 2$ & $t_{0} / 2+\mathrm{t}_{\mathrm{a}}+\mathrm{t}_{\mathrm{b}}$ \\
6 & $t_{0} / 2+\mathrm{t}_{\mathrm{a}}+\mathrm{t}_{\mathrm{b}}$ & $t_{0} / 2$ & $t_{0} / 2+\mathrm{t}_{\mathrm{a}}$ \\
\hline
\end{tabular}

\subsection{Tasarlanan Motor Sürücü Devresi}

Alan yönlendirmeli kontrolün gerçekleştirilebilmesi için SMSM'nin her bir fazına uygulanan gerilim/akım sinyalinin kontrol edilmesi gerekmektedir. Bu amaçla bir SMSM sürücüsü tasarımı ve prototip üretimi gerçekleştirilmiştir.

Gerçekleştirilen sürücü tasarımının karşılayabilmesi gereken teknik özellikler; sistemin çalışmalar esnasında yaşanabilecek olumsuzluklara karşın kolay onarılabilir olması, harici bir yardımcı besleme kaynağına ihtiyaç duymaksızın yalnızca şebeke gerilimi ile çalışabilir olması, motorun tam yük akımlarına uygun çıkış akım kapasitelerine sahip olması, motorun aşırı yüklenme durumlarında çekebileceği muhtemel akımlara karşı belirli süreler boyunca dayanabilecek olması şeklinde sıralanabilir [22]. Ayrıca sürücünün kolay üretilebilir olması açısından yerel piyasada rahatlıkla bulunabilecek malzemeler tercih edilerek tasarlanmış olması da önemli bir husus olarak göz önünde bulundurulmuştur.

Tasarlanan ve gerçekleştirilen motor sürücüsü giriş katı (doğrultucu kısmı), çıkış katı (evirici), dinamik frenleme kıyıcısı, akım geri besleme katı, pozisyon geri besleme katı ve mikrodenetleyici kontrol katı kısımlarından oluşmaktadır. Şekil 6'da özel amaçlı motor sürücü prototipinin temel kısımları görülmektedir.

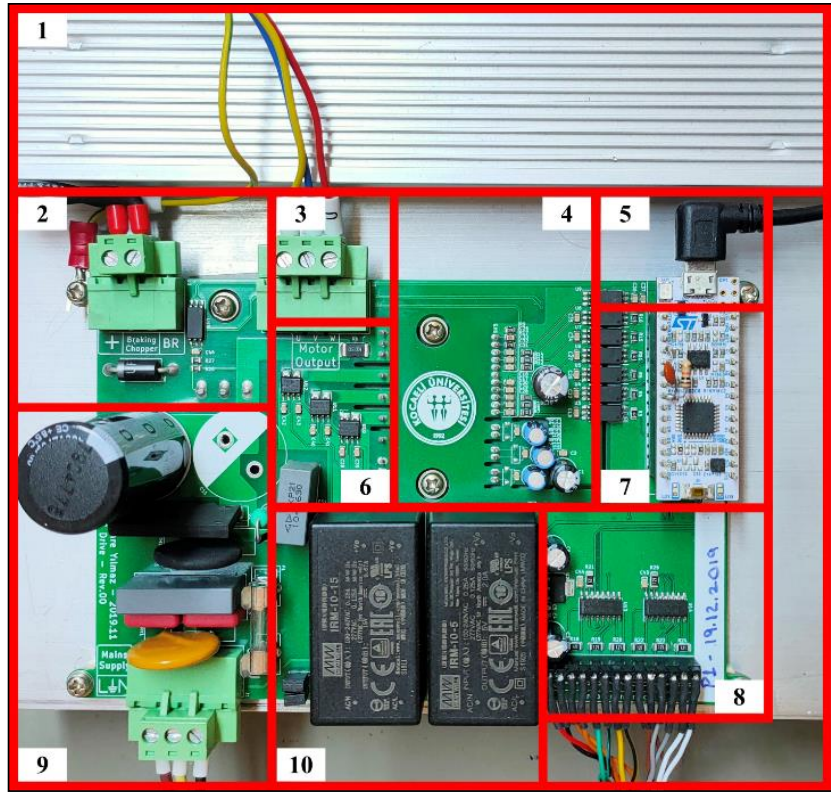

Şekil 6. Tasarlanan özel amaçlı motor sürücüsü prototipinin temel kısımlarının görünümü (1) Dinamik frenleme direnci, (2) Dinamik frenleme kıyıcısı, yardımcı ekipmanları ve direnç bağlantı noktası, (3) Evirici çıkışı, motor bağlantı noktası, (4) Evirici güç modülü ve yardımcı devre elemanları,

(5) Bilgisayar veri aktarımı ve hata ayıklama bağlantı noktası, (6) Akım geri besleme katı, (7)

Mikrodenetleyici kontrol katı, (8) Pozisyon geri besleme katı, enkoder ve alan etkili sensör bağlantı noktası, (9) Giriş katı ve şebeke bağlantı noktası, (10) Yardımcı besleme anahtarlamalı güç kaynakları 


\subsubsection{Giriş (Doğrultucu Kısmı) Katı}

Eviricinin giriş katı, tek fazlı şebeke gerilimi ile çalışmaya uygun olarak tasarlanmıştır. Alternatif akım türündeki şebeke geriliminin doğru akıma dönüştürülebilmesi için girişte $35 \mathrm{~A}$ sürekli akım altında, $1000 \mathrm{~V}$ gerilim seviyesinde çalışmaya uygun tam köprü diyot elemanı kullanılmıştır. Köprü diyot çıkışında üretilecek doğru akım sinyalinin düşük dalgalılık oranına sahip olacak şekilde filtrelenebilmesi için yüksek kapasite değerine sahip $400 \mathrm{~V}$ gerilim altında çalışmaya uygun $150 \mathrm{uF}$ değerinde iki adet paralel bağlı elektrolitik kapasitör kullanılmıştır.

\subsection{2. Çıkış (Evirici Kısmı) Katı}

Eviricinin çıkış katı, üç fazlı motorlarla çalışmaya uygun olarak tasarlanmıştır. Eviricinin çıkış katında tasarım karmaşasının önüne geçmek adına tek kılıfta hem anahtarlama elemanlarını hem de anahtarlama elemanı sürücülerini barındıran güç modülü kullanılmıştır. Kullanılan ürün 450V DA gerilim seviyesinde çalışmaya uygun $600 \mathrm{~V}$ DA gerilim seviyesine dayanıklı anahtarlama elemanları bulunduran, 20A çıkış akımı kapasitesine sahip, dâhili anahtarlama elemanı sürücüleri ve gelişmiş koruma fonksiyonları barındıran Fairchild Semiconductor firmasının ürettiği FNC42060F2 model isimli bir güç modülüdür.

Evirici çıkış katında kullanılan güç modülü ile merkezi kontrol ünitesi arasındaki sinyaller yüksek hızlı optik izolasyon elemanları ile galvanik olarak izole edilmiştir. Bahsi geçen optik izolasyon elemanları ile izole edilen sinyaller, anahtarlama elemanlarının iletime veya kesime geçmesini sağlayan darbe genişlik modülasyonu sinyalleri ve güç modülünün sağladığı hata bilgisi sinyalidir.

Bunun yanında çıkış katında oluşabilecek aşırı akım çekilmesi veya kısa devre durumlarında koruma sağlaması adına güç modülünün aşırı akım hata girişi de aktif olarak kullanılmıştır.

\subsubsection{Dinamik Frenleme Kıyıcısı Tasarımı}

Evirici tasarımında göz önünde bulundurulması gereken bir diğer kısım ise, sistemin ani yavaşlama ya da yerçekimine karşı çalışma durumlarında generatör olarak çalışması esnasında ortaya çıkacak olan enerjinin güç katına zarar vermeden sistemden uzaklaştırılabilmesi gerekliliğidir. Bu durumda sistemin DA bara gerilimi yükselecek ve eğer üretilen enerji gereğinden fazla ise yükselen gerilim seviyesi nedeni ile devre elemanları hasar görecektir. Bunun önüne geçilebilmesi için sistemin DA barasına paralel bağlı bir kıyıcı devresi eklenmelidir. Bu kıyıcı devresi gerektiğinde harici bir frenleme direncini devreye alarak DA bara kapasitörlerini deşarj edecek şekilde çalıştıracaktır. Bu sayede sistemin generatör olarak çalışması esnasında üretilen elektrik enerjisinin 1s1 enerjisine dönüştürülerek sistemden uzaklaştırılmasını sağlayacaktır.

\subsubsection{Akım Geri Besleme Katı Tasarımı}

Alan yönlendirmeli kontrol tekniğinin gerçekleştirilebilmesi için motor faz akımları bilgisine ihtiyaç duyulmaktadır. Bu nedenle tasarım karmaşasını azaltan ve yapısı gereği güç devresi ile kontrol devresi arasında izolasyon sağlayan alan etkili akım ölçümü elemanları kullanılmıştır. Motor üç fazlı dengeli bir yük olduğundan, yalnızca iki faz akımının ölçülmesi yeterlidir. Kullanılan akım ölçümü elemanları $\pm 5 \mathrm{~A}$ ölçüm kapasitesine sahiptirler.

\subsubsection{Pozisyon Geri Besleme Katı Tasarımı}

Alan yönlendirmeli kontrol tekniğinin gerçekleştirilebilmesi için rotor pozisyonu ve rotor hızı bilgilerine ihtiyaç duyulmaktadır.

Bu çalışmada kullanılan SMSM'de Tamagawa Seiki firmasının 2500PPR çözünürlüğündeki 5V DA gerilim ile çalışmaya uygun diferansiyel çıkışlı artımsal enkoder ve alan etkili geri besleme elemanı çıkışları bulunduran pozisyon geri besleme elemanı kullanılmıştır. Bu tip geri besleme elemanları, genellikle evirici çıkışı gibi yüksek frekanslı anahtarlama devreleri ile birlikte kullanıldı̆̆ından, elektromanyetik gürültü kaynaklarından daha az etkilenmeleri ve ürettikleri sinyallerin bozunuma uğramaması için diferansiyel tipte çıkış verecek şekilde tasarlanmaktadırlar. Ancak diferansiyel 
sinyaller merkezi kontrol ünitesine doğrudan uygulanamayacağından, bu sinyallerin kontrol ünitesine uygun hale dönüştürülmesi gerekmektedir. $\mathrm{Bu}$ nedenle pozisyon geri besleme katı tasarımında diferansiyel sinyalleri tekil sinyallere dönüştürebilen bir entegre devre elemanı kullanılmıştır.

Kullanılan entegre devre elemanı, 32MHz frekansını aşmayan diferansiyel sinyalleri tekil sinyallere dönüştürebilmektedir.

\subsubsection{Mikrodenetleyici Kontrol Katı Tasarımı}

Alan yönlendirmeli kontrol tekniğinin uygulanabilmesi için ihtiyaç duyulan matematiksel işlem gücünü ve gerekli sinyal işleme yeteneklerini karşılamak üzere ST firmasının ürettiği ARM firmasına ait 32-bit Cortex-M4 mimarisine sahip STM32F303K8T6 mikrodenetleyici kullanılmıştır.

Temel olarak 6 farklı kısımdan oluşan motor sürücüsü, SMSM'nin alan yönlendirmeli kontrolünü yapmak üzere çalışmada kullanılan deneysel SMSM'ye uygun şekilde özel amaçlı olarak tasarlanmıştır.

\subsection{Deneysel Çalışmalar}

Alan yönlendirmeli kontrol tekniğinin deneysel olarak gerçekleştirilmesi için var olan bir SMSM için özel amaçlı bir motor sürücüsü ve yazılımı gerçekleştirilmiştir. Şekil 3'te verilen alan yönlendirmeli kontrol tekniği prensip şemasına uygun olarak hız ve akım geri besleme sinyalleri ve referans değerler ile mikrodenetleyici kontrol katında gerekli algoritmalar oluşturulmuştur. Bu amaçla uygun faz gerilimlerini üretmek üzere motor sürücüsündeki evirici devresi UVDGM tekniği ile sürülerek deneysel çalışmalar gerçekleştirilmiştir

\subsubsection{Deneysel SMSM}

Deneysel çalışmalarda kullanılan SMSM, rotor mıknatısları yerleşimi bakımından yüzey montajı tipte üç fazlı bir alternatif akım motorudur. Kullanılan SMSM'nin teknik özellikleri Tablo 3'te verilmiştir.

Tablo 3. Kullanılan SMSM'nin teknik özellikleri

\begin{tabular}{cc}
\hline Nominal Güç & $750 \mathrm{~W}$ \\
\hline Nominal Gerilim & $220 \mathrm{~V}$ \\
\hline Nominal Akım & $3 \mathrm{~A}$ \\
\hline Nominal Frekans & $200 \mathrm{~Hz}$ \\
\hline Nominal Hız & 3000 devir/dakika \\
\hline Nominal Moment & $2.39 \mathrm{~N} . \mathrm{m}$ \\
\hline Anlık Moment & $7.1 \mathrm{~N} . \mathrm{m}$ \\
\hline Anlık Akım & $9 \mathrm{~A}$ \\
\hline Moment Katsayıs1 & $0.8 \mathrm{~N} . \mathrm{m} / \mathrm{A}$ \\
\hline Rotor Ataleti & $0.000182 \mathrm{~kg} . \mathrm{m}^{2}$ \\
\hline Rotor Kutup Sayıs1 & 8 \\
\hline Rotor Miknatıs Tipi & $\mathrm{NdFeB}$ \\
\hline Stator Oluk Sayısı & 18 \\
\hline Stator Sarg1 Direnci & $2.88 \Omega$ \\
\hline Stator Sarg1 Endüktans1 & $6.4 \mathrm{mH}$ \\
\hline Elektriksel Zaman Sabiti & $2.22 \mathrm{~ms}$ \\
\hline Ağırlı & $2.9 \mathrm{~kg}$ \\
\hline
\end{tabular}

\subsubsection{Motor Sürücüsü Prototipi}

Motor sürücüsü prototipi gerekli donanım ve yazılım özellikleri ile Bölüm 2.3’te anlatıldığı kısımları içerecek şekilde tasarlanmış ve üretilmiştir. Sürücü prototipinin fotoğrafı Şekil 7'de görülmektedir. 


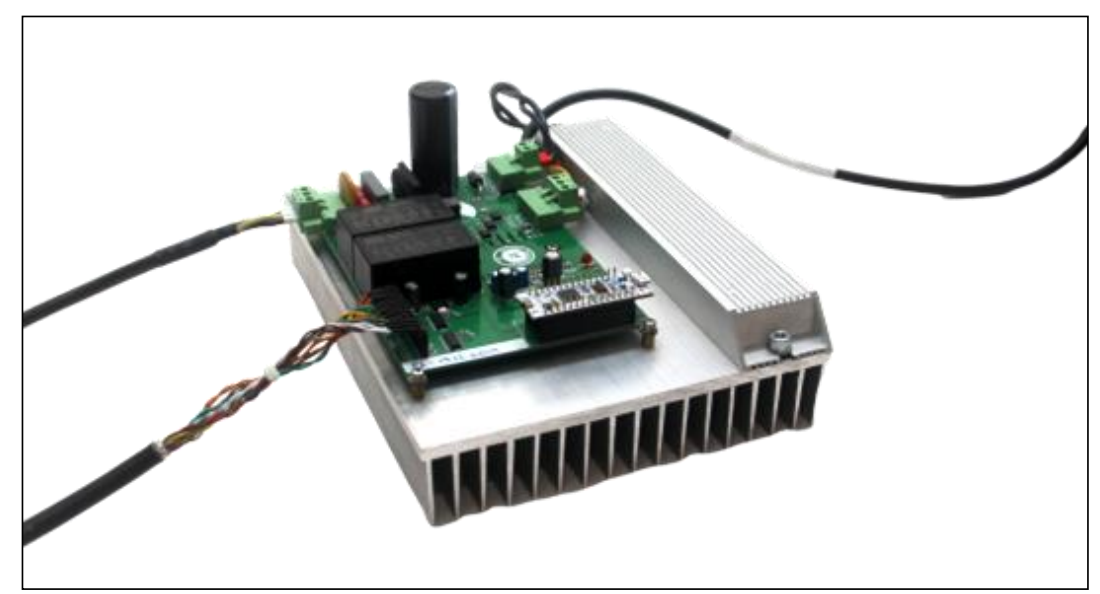

Şekil 7. Tasarımı ve üretimi gerçekleştirilen özel amaçlı sürücü prototipinin genel görünüşü

\subsubsection{Deney Seti}

Motorun testlerini yapabilmek amacıyla bir deney düzeneği oluşturularak farklı koşullar için deneysel çalışmalar yapılmıştır.

Geliştirilen deney düzeneğinde kontrolü gerçekleștirilecek olan SMSM'nin rotor miline karşıt makina olarak bir sincap kafesli asenkron makina (SKAM) bağlanmıştır. Deney setinin görünüşü Şekil 8'de verilmiştir.

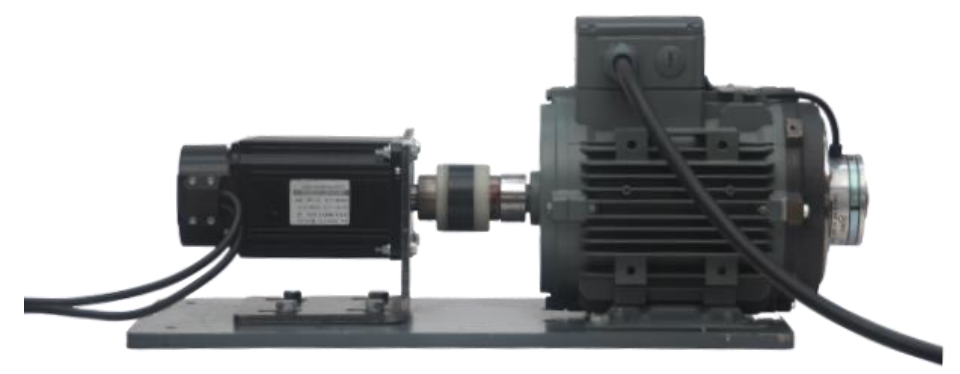

Şekil 8. SMSM (solda) ve SKAM (sağda) kullanılarak geliştirilen deney düzeneği

Mile doğrudan bağlı bulunan SKAM, dinamik çalışma esnasında ihtiyaç duyulacak olan yük koşullarının oluşturulabilmesi amacıyla kullanılmaktadır. Ayrıca buna ek olarak SKAM'nin rotor miline bağlı bulunan manyetik mekanik fren, statik çalışma esnasında ihtiyaç duyulacak olan yük koşullarını oluşturabilmesi amacıyla kullanılmaktadır. Deney düzeneğinde bulunan SKAM, endüstriyel bir hız kontrol ünitesi ile birlikte generatör durumunda çalıştırılarak dinamik bir yük olarak kullanılmaktadır.

\section{Bulgular ve Tartışma}

Deneysel çalışmalar temel olarak belirli yük koşulları altında SMSM'nin alan yönlendirmeli kontrolünün gerçekleştirilmesi üzerine kurgulanmıştır. Deneysel çalışmalarda SMSM'nin boşta, mekanik olarak kilitli rotor durumunda ve farklı yüklenme oranlarında alan yönlendirmeli kontrol tekniği uygulanarak hız ve/veya $i_{q}$ akımını kontrol ederek moment kontrolünün gerçekleştirilmesi amaçlanmıştır.

Gerçekleştirilen deneysel çalışmalarda belirli yük koşullarında elde edilen veriler zamana bağlı grafikler ve osiloskop görüntüleri kullanılarak görselleştirilmiştir.

SMSM rotor mili manyetik mekanik fren vasıtası ile kilitli iken, verilen q ekseni akımı referans değerlerine karşı elde edilen deney sonuçları Şekil 9'da görülmektedir. 


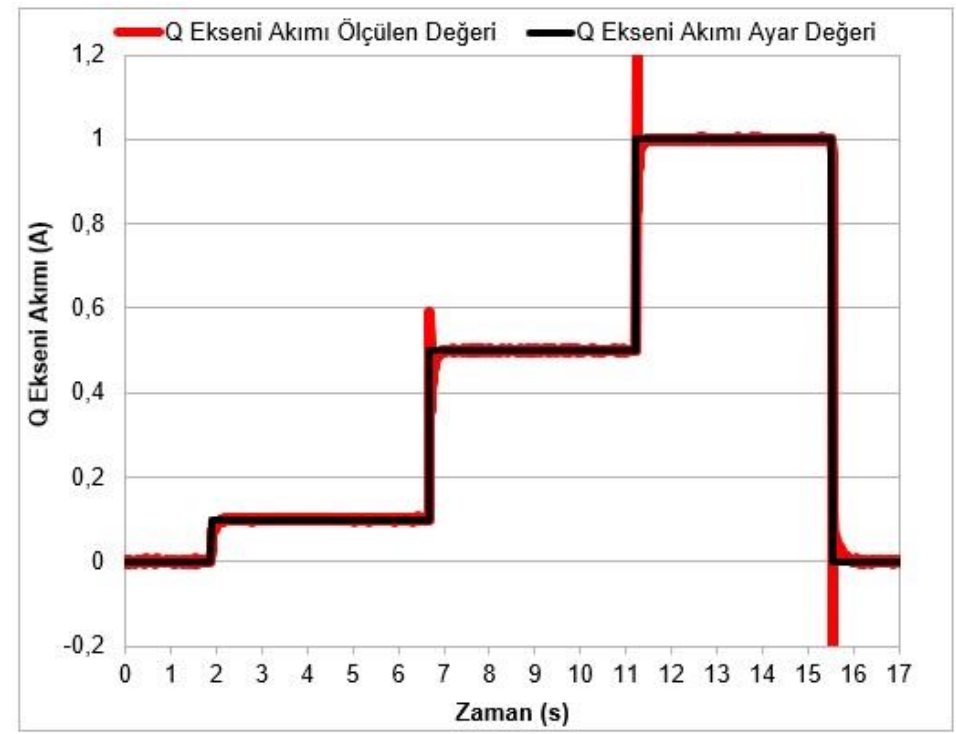

Şekil 9. Kilitli rotor durumunda q ekseni akımının referans değerlerinin 0,1A, 0,5A ve 1,0A yapılmasına karş1lık sistemin davranışı

Şekil 9 incelendiğinde sistemin akım kontrol döngülerinin verilen referans ayar değerlerine kısa zamanda tepki verdiği ve akım değerinin verilen referans değere oturduğu görülmektedir. Böylelikle moment üreten $i_{q}$ akımı kapalı çevrim olarak kontrol edilerek makinanın momenti de dolaylı olarak kontrol edilebilecektir.

SMSM rotor mili boşta iken sisteme verilen hız kontrolü ayar değerine karşı elde edilen deney sonuçları Şekil 10'da görülmektedir.

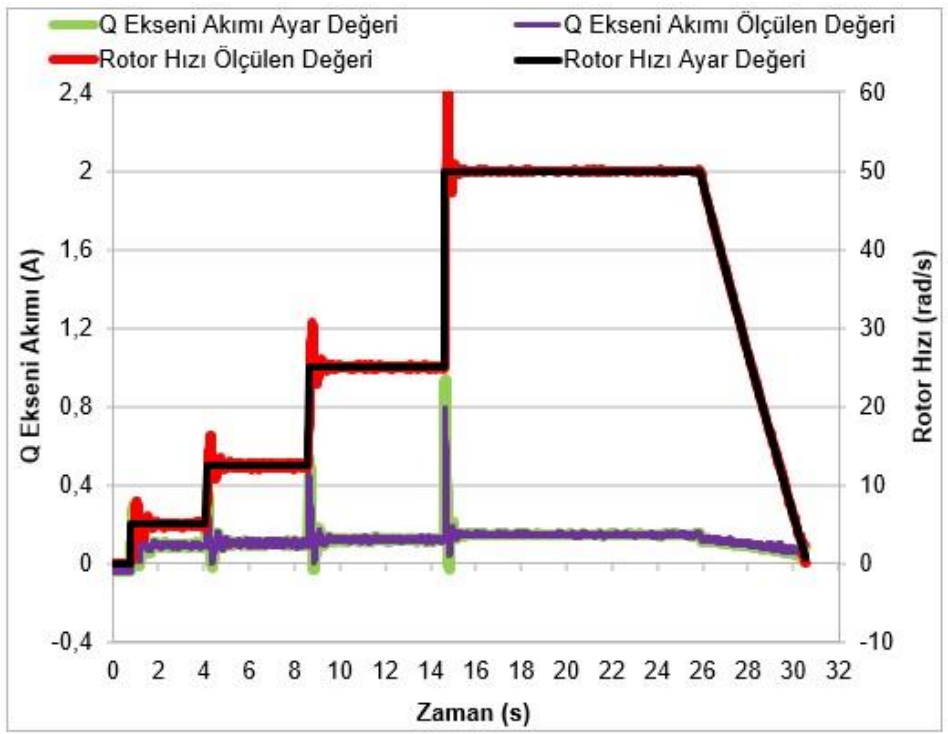

Şekil 10. SMSM boşta iken hız kontrolü referans değerlerinin $5 \mathrm{rad} / \mathrm{s}, 12,5 \mathrm{rad} / \mathrm{s}, 25 \mathrm{rad} / \mathrm{s}$ ve $50 \mathrm{rad} / \mathrm{s}$ ayar değerlerine karşı sistemin davranışı

Şekil 10' dan görüldüğ̈̈ gibi SMSM boşta çalışırken verilen hız referansı değerlerine hızlı bir şekilde tepki vererek motor hızı istene değere oturmaktadır.

SMSM rotor mili değişken hız kontrollü SKAM'ye bağlı iken ve belirli bir yük değeri için sisteme verilen $25 \mathrm{rad} / \mathrm{s}$ hız referansına karşı elde edilen deney sonuçları Şekil 11 ve Şekil 12'de görülmektedir. 


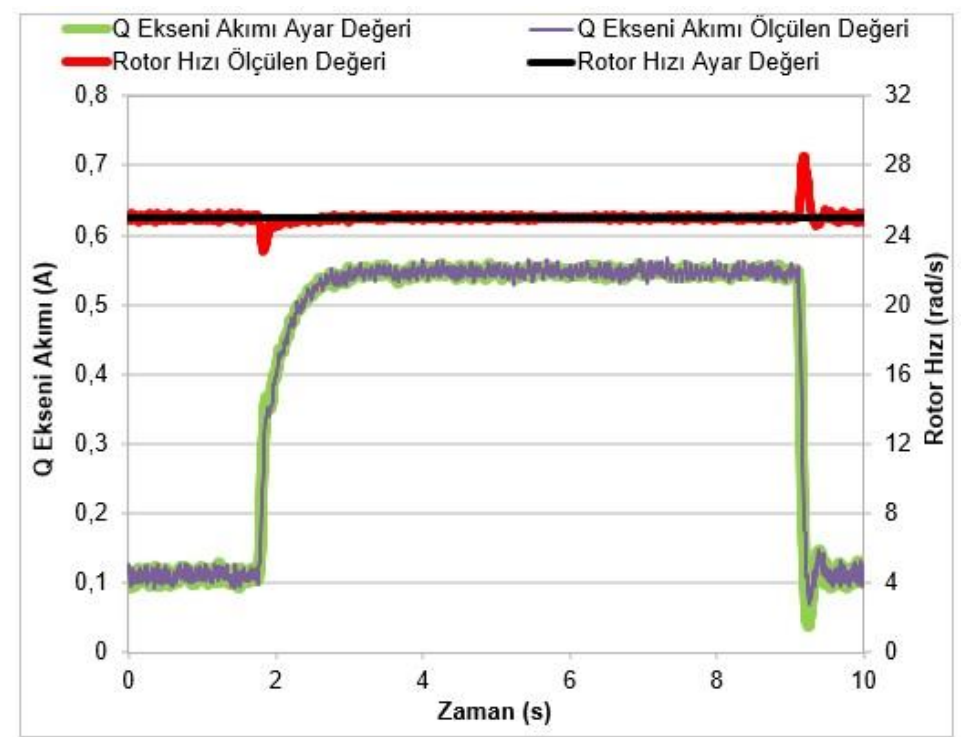

Şekil 11. Hız kontrolü $25 \mathrm{rad} / \mathrm{s}$ ayar değerine ve yaklaşık $0,5 \mathrm{~A}$ q ekseni akımına eş değer dinamik yüklenmeye karşı sistemin tepkisi

Şekil 11'de verilen hız referansı 25rad/s değerindedir. SMSM yüklendiğinde ve yük tekrar kaldırıldığı durumda hız yine verilen referans değeri korumaktadır.

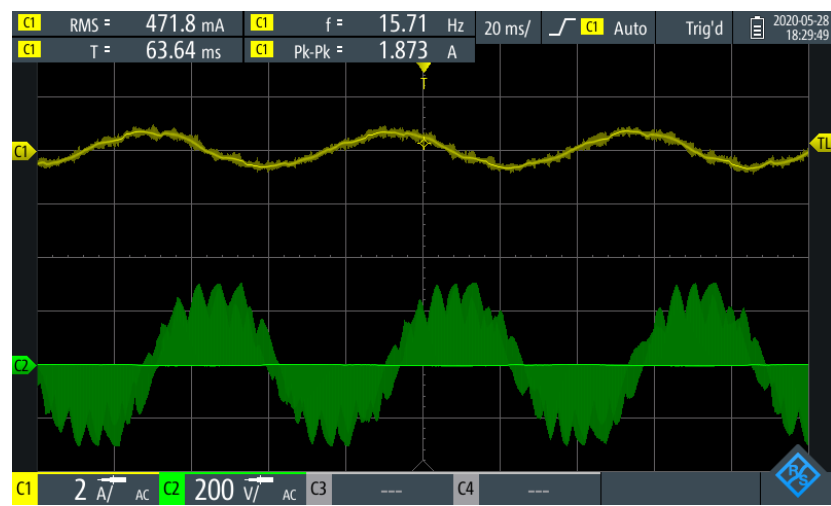

Şekil 12. Hız kontrolü 25rad/s ayar değerine ve yaklaşık 0,5A q ekseni akımına eş değer dinamik yüklenmeye karşı motor bir faz akımı ve evirici çıkış fazları arası gerilim dalga şekilleri

Şekil 12 'de $25 \mathrm{rad} / \mathrm{s} \mathrm{hız} \mathrm{referansı} \mathrm{ve} \mathrm{yaklaşık} 0,5 \mathrm{~A}$ q ekseni akımına eş değer bir dinamik yüklenme sonucu motor bir faz akımının ve faz arası gerilimin osiloskop görüntüsüne yer verilmiştir. $\mathrm{Bu}$ yüklenme durumunda, verilen hız referansına ulaşabilmek amacıyla alan yönlendirmeli kontrol tekniğinde kullanılan uzay vektör modülasyonu sonucu fazlar arası gerilimde yüksek frekanslı anahtarlama yapıldığı görülmektedir. Faz akımı ise sinüsoidaldir.

Deneysel sonuçlar, tasarlanan STM mikrodenetleyici tabanlı motor sürücüsü ile SMSM'nin alan yönlendirmeli kontrolünün başarılı bir şekilde gerçekleştirildiğini göstermiştir. Sistemin akım ve hız referanslarına oldukça dinamik cevaplar verdiği görülmektedir. Ayrıca literatürdeki DSP mikrodenetleyici tabanlı benzer sürücülere göre daha az maliyetli olması bu sürücünün avantajlarından biridir.

\section{Sonuç ve Öneriler}

Bu çalışma kapsamında, alan yönlendirmeli kontrol tekniğinin pozisyon geri beslemeli uygulamasının geliştirilebilmesi için ihtiyaç duyulan özel amaçlı evirici tasarımı ve üretimi gerçekleştirilmiştir. Ayrıca ilgili deneysel çalışmaların tamamlanabilmesi için, kontrolü sağlanan SMSM'nin boşta ve yükte çalıştırılmasına olanak tanıyan deney düzeneği geliştirilmiş̧ir. 
Geliştirilen motor sürücüsü ve yazılım algoritması ile alan yönlendirmeli kontrol tekniği SMSM üzerine başarılı bir şekilde uygulanmıştır. Yapılan deneysel çalışmalar, sistemin istenildiğinde $\mathrm{i}_{\mathrm{q}}$ akımını kontrol ederek dolaylı moment kontrolü veya hız kontrolü amacıyla kullanılabileceğini göstermiştir.

Sistem, pozisyon geri besleme elemanı bulundurması nedeniyle, gerekli değişiklikler yapıldığında, yüksek kararlılıklı pozisyon kontrolü amacıyla da kullanılabilir. Sistemi pozisyon kontrolü amacıyla kullanabilmek için hız kontrol döngüsünün ayar değerinin, sisteme eklenecek pozisyon kontrol döngüsü PI kontrolörünün çıkış değerine eşitlenmesi yeterli olacaktır.

$\mathrm{Bu}$ uygulamalı çalışma, alan yönlendirmeli kontrol tekniğinin endüstriyel hız kontrol cihazı tasarımlarında uygulanması durumunda, ihtiyaç duyulan donanımların azlığından ötürü çok yüksek maliyet artışlarına neden olmadan yüksek güvenilirlikli hız veya pozisyon kontrol sistemlerinin geliştirilebileceğini göstermektedir.

\section{Teşekkür}

Deneysel çalışmaların gerçekleştirilmesi için gerekli ortam ve deney ekipmanlarının sağlanmasında katkıda bulunan Yılmaz Redüktör San. ve Tic. A.Ş. firmasına teşekkür ederiz.

\section{Yazarların Katkısı}

Çalışmada tüm yazarlar eşit oranda katkı sunmuştur.

\section{Çıkar Çatışması Beyanı}

Yazarlar arasında herhangi bir çıkar çatışması bulunmamaktadır.

\section{Araştırma ve Yayın Etiği Beyanı}

Yapılan çalışmada araştırma ve yayın etiğine uyulmuştur.

\section{Kaynaklar}

[1] Günaydın F.Y., Özkara Y. 2016. İmalat Sanayisinde Kullanılan Elektrik Motorları Envanteri Analiz Raporu, T.C. Bilim Sanayi ve Teknoloji Bakanlığı.

[2] Başar M.S., Bech M.M., Andersen T.O., Scavenius P., Thomas-Basar T. 2013. Comparison of Sensorless FOC and SVM-DTFC of PMSM for Low-Speed Applications. 4th International Conference on Power Engineering, Energy and Electrical Drives, 14-16 May1s, İstanbul.

[3] Brandstetter P., Neborak I., Kuchar M. 2017. Analysis of Steady-State Error in Torque Current Component Control of PMSM Drive. Advances in Electrical and Computer Engineering, 17 (2): 39-46.

[4] Zhang X., Xiaohua X., Yao R. 2015. Field Oriented Control for Permanent Magnet Synchronous Motor Based on DSP Experimental Platform, The 27th Chinese Control and Decision Conference, 23-25 May1s, Qingdao.

[5] Yeşilbağ E., Ergene L.T. 2014. Field Oriented Control of Permanent Magnet Synchronous Motors Used in Washers. 16th International Power Electronics and Motion Control Conference and Exposition, 21-24 Eylül, Antalya.

[6] Adhavan B., Kuppuswamy A., Jayabaskaran G., Jagannathan V. 2011. Field Oriented Control of Permanent Magnet Synchronous Motor (PMSM) Using Fuzzy Logic Controller. IEEE Recent Advances in Intelligent Computational Systems, 22-24 Eylül, Trivandrum.

[7] Harib K.H., Khousa E.A., Ismail A. 2004. Field Oriented Motion Control of a 3-Phase Permanent Magnet Synchronous Motor. 2nd International Conference on Electric Power and Energy Conversion Systems, 16-19 Ağustos, Sharjah.

[8] Çelik H., Yiğit T. 2018. Field-Oriented Control of the PMSM with 2-DOF PI Controller Tuned by Using PSO. International Conference on Artificial Intelligence and Data Processing, 28-30 Eylül, Malatya. 
[9] Wang X., Liu N., Na R. 2009. Simulation of PMSM Field-Oriented Control Based on SVPWM. IEEE Vehicle Power and Propulsion Conference, 7-11 Eylül, Dearborn.

[10] Samat A.A.A., Ishak D., Saedin P., Iqbal S. 2012. Speed-sensorless Control of Parallel-connected PMSM Fed by a Single Inverter Using MRAS. IEEE International Power Engineering and Optimization Conference, 6-7 Haziran, Melaka.

[11] Wang Z., Chen J., Cheng M., Chau K. T. 2016. Field-Oriented Control and Direct Torque Control for Paralleled VSIs Fed PMSM Drives with Variable Switching Frequencies. IEEE Transactions on Power Electronics, 31 (3): 2417-2428.

[12] Lara J., Xu J., Chandra A. 2016. Effects of Rotor Position Error in the Performance of FieldOriented-Controlled PMSM Drives for Electric Vehicle Traction Applications. IEEE Transactions on Industrial Electronics, 63 (8): 4738-4751.

[13] Yao H., Yan Y., Shi T., Zhang G., Wang Z., Xia C. 2021. A Novel SVPWM Scheme for Field Oriented Vector Controlled PMSM Drive System Fed by Cascaded H-Bridge Inverter. IEEE Transactions on Power Electronics, 36(8): 8988-9000.

[14] Sun T., Liu C., Lu N., Gao D., Xu S. 2012. Design of PMSM Vector Control System Based on TMS320F2812 DSP. Proceedings of the 7th International Power Electronics and Motion Control Conference, Harbin, China.

[15] Sang Y., Li F., Dai Y., Duan F. 2015. The Practical Control Technology Design for AC Servo Motor Based on STM32 Micro-controller, IEEE Advanced Information Technology. Electronic and Automation Control Conference, 19-20 Aralık, Chongqing, China.

[16] Belhamel L., Buscarino A., Cucuccio A., Fortuna L., Rascona G. 2020. Model-Based Design Streamlines for STM32 Motor Control Embedded Software System. 7th International Conference on Control, Decision and Information Technologies, 29 Haziran-2 Temmuz, Prague, Czech Republic.

[17] Qian Z., Guo Q., Pham M. -T., Li W. 2019. Design of a Low Power Consumption Control System of Permanent Magnet Synchronous Motor for Automated Guided Vehicle. 22nd International Conference on Electrical Machines and Systems, 11-14 Ağustos, Harbin, China.

[18] Duesterhoeft W.C., Schulz M.W., Clarke E. 1951. Determination of Instantaneous Currents and Voltages by Means of Alpha, Beta, and Zero Components. Transactions of the American Institute of Electrical Engineers, 70 (2): 1248-1255.

[19] Pillay P., Krishnan R., 1988. Modeling of Permanent Magnet Motor Drives. IEEE Transactions on Industrial Electronics, 35 (4): 537-541.

[20] Zhou K., Wang D. 2002. Relationship Between Space-Vector Modulation and Three-Phase Carrier-Based PWM: A Comprehensive Analysis. IEEE Transactions on Industrial Electronics, 49 (1): 186-196.

[21] Ahmed W., Ali S. 2013. Comparative Study of SVPWM (Space Vector Pulse Width Modulation) $\&$ SPWM (Sinusoidal Pulse Width Modulation) Based Three Phase Voltage Source Inverters for Variable Speed Drive. IOP Conference Series: Materials Science and Engineering, 24-26 Haziran, Karachi.

[22] Yılmaz H.C. 2020. Sürekli Mıknatıslı Motorun Alan Yönlendirmeli Kontrolü. Yüksek Lisans Tezi, Kocaeli Üniversitesi, Fen Bilimleri Enstitüsü, Kocaeli. 